\title{
International Repercussions of Source-based Capital Income Taxation
}

\author{
Thomas Alslev Christensen and Søren Bo Nielsen \\ Economic Policy Research Unit, \\ Copenhagen Business School
}

\begin{abstract}
The paper is concerned with international effects of source-based capital income taxation in a large economy. We derive, within the context of a twocountry overlapping generations model in continuous time, the implications of such taxation for the world interest rate and for investment, consumption, saving and external balances at home and abroad. Furthermore, we argue that higher source-based taxes will hurt foreigners alive at the time of the policy change, whereas future citizens abroad stand to benefit. Finally, the effects of source-and residence-based taxes are compared.
\end{abstract}

\section{Introduction}

This paper examines the international spill-over effects of capital income taxation in large countries. Our main focus will be on taxation of capital income on the basis of the so called source-principle.

* Economic Policy Research Unit, Copenhagen Business School, Nansensgade 195, DK-1366 København K, (Tel) 3815 25 96, (Fax) 381526 65; e-mail: sbn/eco@cbs.dk; Earlier versions of the paper were presented at a ESF/CEPR Conference on International Taxation, Bergen, and the 1993 SEDC Conference in Nafplio. We thank, among others, Agnar Sandmo and Chi-Wa Yuen for comments.

C1995 - Institute for International Economics, Sejong Institution. All rights reserved. 
Concerning taxation of capital income in an international context it is customary to distinguish between two basic principles for taxation, namely the source principle and the residence principle. According to the former principle, capital income will be taxed, where it is generated, regardless of the nationality of the final recipient of the income flow. According to the latter principle, income is taxed at the point of the final recipient. National tax systems in industrialized countries may be perceived as mixtures of these two polar systems of taxation. Indeed, the corporate income tax is essentially designed to be a source-based tax, whereas capital income taxation at the personal level (interest and dividend taxation) is essentially residencebased.

The usual questions asked in comparisons of the source and residence principles have to do with their effects on saving and capital formation. Do the taxes levied on the basis of these principles distort saving or do they distort investment? Likewise, it is inquired whether the principles obey socalled "capital export neutrality", meaning that the tax system offers no incentive to invest at home rather than abroad, or whether they conform with "capital import neutrality", implying that domestic and foreign suppliers of capital to a given national market obtain the same after-tax return to their investment in the market. In broad terms, capital income taxation according to the source principle will distort investment and will be unable to secure capital export neutrality. However, it will not directly distort saving, and it is compatible with capital import neutrality. Residence-based taxation has exactly the opposite properties.

In this article, we intend to take some further steps in the characterization of the basic principles of international capital taxation. We shall especially be concerned with the macroeconomic consequences and the intergenerational welfare implications of a change in the capital income tax rate in a large country, when it adheres to the source principle. Our medium of analysis is a two-country, continuous-time overlapping generations model featuring a number of macroeconomic key variables and enabling stringent welfare investigation. In doing so we build on earlier work on the effect of capital income taxation in open economies, cfr. Sinn [1985, 1987], Nielsen and Sørensen [1991], Bovenberg [1989, 1993, 1994], Sibert [1990], Ihori [1991] and Nielsen [1992]. Sinn's analysis is essentially a static one, while 
the other contributions contain dynamic analysis of capital income taxation in either small countries 〈Nielsen and Sørensen, Bovenberg [1993, 1994]〉 or large countries.

Among the latter, Bovenberg [1989] studies the effects on international competitiveness and trade balance of source-based taxation, while Sibert principally examines the steady state consequences of investment and savings taxes in a two-period overlapping generations model. Ihori discusses, in a model similar to Sibert's, tax reform in a large country, whereby an exogenous increase in a consumption tax is financed by a decline in capital income taxation. But the article most closely related to the present article is Nielsen [1992], in which an investment subsidy and also residence-based capital income taxation are analyzed.

The plan of the paper is as follows. Section II sets up a two-country, continuous-time overlapping generations model; the demographic part of the model is as in Buiter [1988], but in addition we include capital accumulation and taxation of income from capital.

Section III explains how the model is solved by reference to two 'pseudoeconomies', the 'average' and 'difference' economies in a manner suggested by Aoki [1981]. From this we move on to derive short and long run macroeconomic impacts in each of the two original countries if the home country raises its source-based capital income tax. This is the agenda for section IV. We find, for instance, that the tax will on impact raise consumption abroad, whereas the long run consequences for consumption in the foreign country is a fall. Furthermore, the tax will raise the capital intensity abroad while leading to a deterioration of the net foreign asset position there. And in the long run, financial wealth abroad will decline.

The model we use allows us to investigate the welfare consequences of capital income taxation for foreign residents in the present and in the future. According to our calculations in section V, a source-based capital income tax at home will lower welfare on the part of average foreign citizens alive at the time of the tax change, whereas foreigners born in the (distant) future will benefit from the tax.

Our model may also be used to derive results for macroeconomic and welfare implications of taxation according to the residence principle. We rarely provide explicit calculations for this principle, since the macroeco- 
nomic effects of residence-based capital income taxes in a large country were dealt with in a similar framework in Nielsen [1992]. However, at several stages in sections IV and V we do take the opportunity to underline significant differences in the effects of taxation according to the source and residence principles.

The final section VI provides a brief discussion of the results and the model we have applied.

\section{A Two-country Model}

In this section we set up our medium of analysis, a two-country, continuous-time overlapping generations model. This model is in the tradition of Blanchard [1985] and Buiter [1988] and is closely related to that in Nielsen [1992]. Similar models of capital income taxation, albeit for small open economies, are found in Nielsen and Sørensen [1991] and Bovenberg [1993, 1994].

The two countries in the model are labeled the home country and the foreign country, respectively. For computational convenience, they are assumed to be completely symmetric to start with. Apart from having identical size and identical demographic and behavioural characteristics, they also have the same rates of capital income taxation to start with. This enables us to utilize the famous "Aoki-trick" 〈Aoki [1981]) in solving the model.

Besides reasons of computational convenience, the symmetry assumptions can also be defended by reference to the character of this study. We want to focus on typical own-country and transmission effects of sourcebased capital tax policy, rather than on the consequences of certain asymmetries. Moreover, when setting up the two-country model below, we need only be specific about the relations pertaining to one of the economies, in casu the home country.

Only one good (the same good) is produced in each country. Production factors are capital and labour. The production technology displays linear homogeneity and has conventional properties. While labour is internationally immobile, capital - in fact both "financial" capital and "physical" capital will be assumed fully mobile internationally. But regardless of the implied assumption of the possibility of instantaneous "reshuffling" of physical capi- 
tal between the two countries, there are limits as to how quickly capital can be built up in both countries, since the implied investment must be financed out of world savings. As a consequence, an abrupt increase in world investment demand, say, will in the short run affect the international interest rate instead.

In principle, every agent in the world economy might have access to several types of financial assets. Since we, however, do not want to focus on budget deficits and public indebtedness in this paper, we shall assume that the stock of public debt is zero in both countries. Furthermore, we actually do not have to distinguish between the two investment options that are alternatives to investing in the home capital stock: foreign lending on the one hand and direct investment in the foreign capital stock on the other. The reason for this is that they are considered perfect substitutes; that the source-based (or residence-based) capital income taxes we study feature uniform taxation of the relevant capital income; and that we choose to ignore costs of adjustment of physical capital.

We now proceed by describing the behaviour of consumers, firms and the public sector in the home country.

\section{A. Consumers}

We utilize the same demographic set-up as in Buiter [1988]. Hence, at each instant new individuals are born at the rate $\beta$ while existing individuals die away at the rate $\lambda$. Thereby, the population growth rate, $\mu$, becomes $\mu=\beta-\lambda$. Labour supply on the part of all individuals is assumed fixed (at unity).

Consider an individual born at some time $v$. His consumption, financial wealth and human capital (the discounted sum of his future wage income and transfers from the public sector) at a later instant, $t$, will be denoted by $c(v, t), a(v, t)$ and $j(t)$, respectively. Since all consumers receive the same wage payment and also the same rate of transfer from the public sector, human capital is age-independent; hence the notation $j(t)$.

Faced with an expected stream of wages $w$ and transfers $\tau$ in the future and with an after-tax interest rate $\tilde{r}(t)$, he maximizes utility from consumption over his remaining lifetime. To discount future felicity he uses a con- 
stant rate of pure time preference, $\delta$. This maximization is done subject to the constraint that consumption must be financed by income over time plus his initial financial wealth. We take his current period-utility function to be iso-elastic, i.e. displaying a constant elasticity of intertemporal substitution. It is well-known that this optimization program results in the consumption rule

$$
c(v, t)=\theta(t)^{-1}(a(v, t)+j(t))
$$

$\theta^{-1}$ is the propensity to consume out of total wealth, $a(v, t)+j(t)$, where $\theta$ is defined by

$$
\theta(t)=\int_{t}^{\infty} \exp \left(\frac{1}{\sigma} \int_{t}^{s}[(1-\sigma)(\tilde{r}(y)+\lambda)-(\delta+\lambda)] d y\right) d s
$$

Here, $\sigma$ is the inverse of the intertemporal substitution elasticity; the net interest rate $\tilde{r}(t)$ is net of any residence-based tax and is defined by

$$
\tilde{r}(t)=r(t)(1-u)
$$

where $u$ is the rate of residence-based capital income taxation and $r$ the world rate of interest.

The individual's budget constraint in flow terms is

$$
\dot{a}(v, t)=[\tilde{r}(t)+\lambda] a(v, t)+w(t)+\tau(t)-c(v, t)
$$

Individual financial wealth is enhanced by interest payments on financial wealth, wage income and transfers, and reduced by consumption.

The change over time in the propensity to consume is given by

$$
\dot{\theta}(t)=-1-\sigma^{-1}[(1-\sigma)(\widetilde{r}(t)+\lambda)-(\delta+\lambda)] \theta(t)
$$

We may note that in the special case of logarithmic current-period utility, $\sigma=1$ and therefore $\theta$ constant at $(\delta+\lambda)^{-1}$.

The size of population is set equal to one at time zero and therefore equals $\exp (\mu t)$ at time $t$. With each individual supplying one unit of labour total employment is likewise $\exp (\mu t)$. When aggregating over individuals we obtain the following expressions for the dynamic evolution of per capita consumption and per capita financial wealth, 


$$
\dot{c}(t)=\sigma^{-1}[\tilde{r}(t)-\delta] c(t)-\beta \theta(t)^{-1} a(t)
$$

and

$$
\dot{a}(t)=[\tilde{r}(t)-\mu] a(t)+w(t)+\tau(t)-c(t)
$$

Financial wealth on the part of consumers is composed of shares in the domestic capital stock and shares in the foreign capital stock (or net foreign lending).

\section{B. Firms}

Production per unit of labour is given by $q(k(t))$, where $k(t)$ stands for the capital intensity in the home country at time $t$. The capital stock depreciates at the rate $\rho$. The marginal return to capital net of depreciation, denoted by $R(t)$, hence is

$$
R(t)=q^{\prime}(k(t))-\rho
$$

The tax base for source-based taxation is the total factor remuneration of domestic capital, net of depreciation. Per unit of labour this can be written as $R(t) k(t)$ because of the constant returns to scale assumption, whence the tax on capital income is $z R(t)$ per unit of capital, $z$ being the source-based tax rate. Since instead of investing in the domestic capital stock an investor can place funds in the international capital market and obtain the world interest rate $r$, the following arbitrage equation must obtain,

$$
(1-z) R(t)=r(t)
$$

Observe that since we do not include costs of adjusting the capital stock, the value of one unit of the capital stock will never deviate from one. In the absence of capital gains or losses, the arbitrage equation becomes relatively simple as in (9).

\section{The Public Sector}

The public sector in the model only performs two functions; it levies capital income taxes according to the source (or residence) principle, and it hands out the revenue from taxation in the form of equal transfers to all 
domestic individuals. Its budget always balances as shown in

$$
\tau(t)=u r(t) a(t)+z R(t) k(t)
$$

Tax revenue in per capita terms is on the right hand side, while the resulting rate of transfer appears on the left hand side. Observe that each type of tax is levied at a uniform rate. ${ }^{1}$

\section{Rate of Return Variables}

It may be helpful to observe that we in effect distinguish between three different interest rates/rates of return in the model. On the one hand $R$ symbolizes the rate of return on domestic physical capital, net of depreciation but before source-based taxes. Then $r$ stands for the rate of return to capital, net of source-based taxes, and this must also be the world rate of interest, since investing in the domestic capital stock is a perfect substitute for investing in the international capital market. $r$ is furthermore measured before possible residence-based taxation; the corresponding interest rate, net of a residence-based tax, was denoted by $\tilde{r}$.

While $r$ is common to the two countries, $R$ and $\tilde{r}$ in general are not as they will reflect possible differences in the extent of source- or residence based taxation across countries. At the outset we shall, though, assume equal tax rates in the two countries.

\section{E. Asset Accumulation}

Financial wealth $a$ consists of shares in the domestic capital stock plus net foreign assets. We shall denote the net foreign asset position by $f$. Using the definition of public transfers in equation (10), equation (7) can also be written

$$
\dot{k}(t)+\dot{f}(t)=q(k(t))+(r(t)-\mu) f(t)-c(t)-(\rho+\mu) k(t)
$$

1. This secures that a source-based tax and a residence-based tax can operate simultaneously and still be compatible with arbitrage and perfect substitutability of assets; this can be inferred from the discussion of 'viable' tax systems in Frenkel et al. (1991, pp. 25-26). 
The stock of total assets will increase, provided the sum of production and the growth-corrected return on net foreign assets exceeds consumption and investment necessary to keep the capital intensity constant.

For the foreign country we have equations similar to the ones above, involving foreign country variables denoted by asterisks.

\section{Tax Changes in the Average and Difference Economies}

To derive results for the effects of changes in tax rates on economic variables in the home and foreign countries we utilize the "Aoki-trick", whereby we first study the dynamic behaviour of the "average economy" and the "difference economy". This analysis is, however, of interest in itself since it informs about how the world economy as a whole will be hit, and to which degree the two countries will be differentially affected. ${ }^{2,3}$

Let $x$ be any variable in the home country and $x^{*}$ the corresponding one for the foreign country. Then define $x^{a}=\left(x+x^{*}\right) / 2$ to be the relevant variable for the average economy and $x^{d}=\left(x-x^{*}\right)$ to be the relevant variable for the difference economy. (Note that $x=x^{a}+x^{d} / 2$, and $x^{*}=x^{a}-x^{d} / 2$ ).

Suppose the world economy is in a steady state prior to time zero. Then, at time zero, a discrete and once-and-for-all change in $z(u)$ takes place, in turn changing $z^{a}$ and $z^{d}$ ( $u^{a}$ and $u^{d}$ ). We now study how such alterations of tax policy will affect the average and difference economies.

From (8) and the arbitrage equation (9) we get

$$
\begin{aligned}
& d r=(1-z) q^{\prime \prime}(k) d k^{a}-R d z^{a} \\
& d k^{d}=\frac{R d z^{d}}{(1-z) q^{\prime \prime}(k)}
\end{aligned}
$$

Equation (12) shows how the world interest rate is affected by a rise in the home country source-based capital income tax rate - and how it varies over time with the size of the average capital stock in the world economy. From (13) we infer that the difference between capital stocks in the two countries

2. Notice that we suppress the time argument in what follows.

3. The average economy performs like a closed economy, while the difference economy can be perceived as a small open one. 
goes down once-and-for-all with a rise in the difference between sourcebased tax rates. Domestic capital is instantaneously shuffled abroad, and in return the domestic net foreign asset position improves.

\section{A. The Average Economy}

When the model variables are formulated as averages, the linearized dynamic system reads:

$$
\begin{aligned}
& {\left[\begin{array}{c}
\dot{c}^{a} \\
\dot{k}^{a} \\
\dot{\theta}^{a}
\end{array}\right]=\left[\begin{array}{ccc}
(\tilde{r}-\delta) \sigma^{-1} & \sigma^{-1} c(1-z)(1-u) q^{\prime \prime}-\beta \theta^{-1} & \beta \theta^{-2} k \\
-1 & R-\mu & 0 \\
0 & -\sigma^{-1} \theta(1-\sigma)(1-z)(1-u) q^{\prime \prime} & \theta^{-1}
\end{array}\right] \cdot\left[\begin{array}{c}
d c^{a} \\
d k^{a} \\
d \theta^{a}
\end{array}\right]} \\
& +\left[\begin{array}{cc}
-\sigma^{-1} c R(1-u) & -\sigma^{-1} c R(1-z) \\
0 & 0 \\
\sigma^{-1}(1-\sigma) \theta R(1-u) & \sigma^{-1}(1-\sigma) \theta R(1-z)
\end{array}\right] \cdot\left[\begin{array}{c}
d z^{a} \\
d u^{a}
\end{array}\right]
\end{aligned}
$$

where we have used the symbol " $\infty$ " to denote steady state values of $c^{a}, k^{a}$ and $\theta^{a}$.

Since the average system is governed by two forward-looking variables, $c^{a}$ and $\theta^{a}$, and one predetermined variable, $k^{a}$, the determinant of the system (multiplied by $\theta$ ), i.e. $\Delta_{a}=\sigma^{-1}(\tilde{r}-\delta)(R-\mu)-\beta \theta^{-1}+\sigma^{-1}[c+\beta k(1-\sigma)](1-z)$ $(1-u) q^{\prime \prime}(k)$, must be negative as a necessary condition for the system to exhibit the saddle point property. ${ }^{4}$ From (14) we derive

$$
d c_{\infty}^{a}=(R-\mu) d k_{\infty}^{a}=\Delta_{a}^{-1}(R-\mu) \gamma R \cdot\left[(1-u) d z^{a}+(1-z) d u^{a}\right]
$$

where $\gamma=[c+\beta k(1-\sigma)] \sigma^{-1}$. ${ }^{5}$ Accordingly, there exists a negative steady state relationship between global consumption and capital accumulation on one side and the average rates of source-based (residence-based) taxation

4. We shall assume that $\tilde{r}-\mu>0$, and thereby that both $r$ and $R$ exceed $\mu$. Accordingly, the equilibrium features underaccumulation and Pareto efficiency. In the appendix it is shown that saddle-point stability is fulfilled in the special case of logarithmic utility, Cobb-Douglas production structure, and no initial taxes.

5. We assume here and in what follows that $\gamma$ is positive; this puts an upper limit on $\sigma$ which is likely to be met empirically. 
on the other. Both types of taxes will depress investment and saving in the world economy, slow down capital accumulation and thus lead to diminished consumption opportunities in the long run. As will be more clear later on, the source-based tax tends to depress investment in the home country, whereas the residence-based tax tends to lower saving there. But for the world economy as a whole it makes no difference, whether the initial impulse comes from a decrease in the home country's investment or in its saving. 6

\section{B. The Difference Economy}

The difference in the stock of physical capital between the two countries was already found in (13). From (3) and (13) we then get $d \tilde{r}^{d}=-r d u^{d}$. Using (5) and the corresponding foreign equation gives us $d \theta^{d}=-\sigma^{-1} \theta^{2}(1-\sigma) r d u^{d}$. Since $\theta$ is the reciprocal of the propensity to spend out of total private wealth, $d \theta^{d}$ can be said to register the change in domestic residents' propensity to save rather than consume relative to foreign country residents. A higher domestic residence-based tax (a lower net interest rate) will raise or lower the propensity to save on the part of domestic citizens depending on the size of the parameter $\sigma$.

On the basis of (6) and (11) and the results just obtained we can set up a two-dimensional linear differential equation system for the difference system. Stated in state-space form it reads:

$$
\begin{aligned}
{\left[\begin{array}{l}
\dot{c}^{d} \\
\dot{f}^{d}
\end{array}\right]=} & {\left[\begin{array}{cc}
(\tilde{r}-\delta) \sigma^{-1} & -\beta \theta^{-1} \\
-1 & r-\mu
\end{array}\right] \cdot\left[\begin{array}{l}
d c^{d} \\
d f^{d}
\end{array}\right] } \\
& +\left[\begin{array}{cc}
-\beta \theta^{-1}\left[(1-z) q^{\prime \prime}\right]^{-1} R & -r \gamma \\
(R-\mu)\left[(1-z) q^{\prime \prime}\right]^{-1} R & 0
\end{array}\right] \cdot\left[\begin{array}{c}
d z^{d} \\
d u^{d}
\end{array}\right]
\end{aligned}
$$

Saddle point stability of the difference system requires that $\Delta_{d}=\sigma^{-1}(\tilde{r}-\delta)$ $(r-\mu)-\beta \theta^{-1}<0$, where $\Delta_{d}$ is the determinant to the Jacobian of system (16). The steady state effects of a change in $z^{d}$ are:

6. Equivalently, the distinction between source-based and residence-based taxes is irrelevant for a closed economy. 


$$
\begin{aligned}
& \frac{d c_{\infty}^{d}}{d z^{d}}=\frac{-\beta R^{2} z}{(1-z) q^{\prime \prime}(k) \theta \Delta_{d}} \leq 0 \\
& \frac{d f_{\infty}^{d}}{d z^{d}}=\frac{-\Delta_{1} R}{(1-z) q^{\prime \prime}(k) \Delta_{d}}>0
\end{aligned}
$$

In $(17 \mathrm{~b}), \Delta_{1}=\sigma^{-1}(\tilde{r}-\delta)(R-\mu)-\beta \theta^{-1}$.

An increase in the source-based tax at home in general leads to lower consumption at home than abroad in the long run and improves the net foreign asset position domestically. In the special case of $z=0$ initially, however, there will be no consequences for the difference between consumption at home and abroad in the long run. ${ }^{8}$

A rise in the residence-based tax at home can be shown to result in lower relative consumption in the new steady state in the domestic economy, and it is also characterized by a deterioration of its net foreign asset position.

\section{Macroeconomic Transmission of Source-based Capital Income Taxes}

On the basis of the foregoing analysis of the average and difference economies we can now study the impact and steady state effects of an increase in domestic capital income taxes on the foreign country and on the home country. ${ }^{9}$ The results are summarized in Table 1 . The primary effect of an increase in the rate of source-based capital income tax at home is to depress the rate of return on physical investment in the home country, cfr.

7. Notice that $\Delta_{d}=\Delta_{1}$ if, and only if, $z=0$. As with the system for the average economy, stability is ensured in the special case of logarithmic utility, Cobb-Douglas production structure, and no initial taxes (see appendix).

8. This effect corresponds to that of an introduction of a corporate tax in a small open economy with zero net foreign asset position and no public debt, cfr. Nielsen and Sørensen [1991].

9. To calculate the steady state effect of an increase in $z$ on, say, foreign consumption ${ }^{*}$, we utilize the formula

$$
\frac{d c_{\infty}^{*}}{d z}=\left(\frac{d c_{\infty}^{a}}{d z^{a}}-\frac{d c_{\infty}^{d}}{d z^{d}}\right) / 2
$$

Similar formulas apply to all other steady state and impact effects. The impact effects for the average and difference economies can be found in the appendix (for the source-based tax). 
(9). The resulting gap between rates of return on capital at home and abroad will lead to an instantaneous outflow of physical capital to the rest of the world, permanently reducing the relative stock of capital in the home country (see (12)). In this process, the after-tax rates of return on capital will be equalized across countries at a lower level than previously; hence, the world interest rate will be driven down as in (13). A lower interest rate will tend to depress world savings, and in the course of time it will set itself through in lower financial wealth worldwide.

The flip side of the inflow of physical capital to the foreign country on impact is a deterioration of its net foreign asset position. As a consequence, it will subsequently have to service this foreign debt. Finally, due to the fall

\section{Table 1}

\section{Impact and Steady State Effects of a Home Country Capital Income Tax, Source-based or Residence-based.}

\begin{tabular}{|c|c|c|c|c|c|}
\hline & \multicolumn{4}{|c|}{ Increase in } \\
\hline & & \multicolumn{2}{|c|}{$z$} & \multicolumn{2}{|c|}{$u$} \\
\hline & & $i m p .^{a}$ & s.s. & $i m p .^{a}$ & s.s. \\
\hline \multicolumn{2}{|c|}{ World interest rate } & - & - & 0 & + \\
\hline Home country & $\begin{array}{l}\text { Consumption } \\
\text { Capital Intensity } \\
\text { Net Foreign Assets } \\
\text { Financial Wealth } \\
\text { After-tax Interest Rate }\end{array}$ & $\begin{array}{l}+^{c} \\
- \\
+ \\
0 \\
-\end{array}$ & $\begin{array}{l}- \\
- \\
+ \\
- \\
-\end{array}$ & $\begin{array}{l}+ \\
0 \\
0 \\
0 \\
-\end{array}$ & $\begin{array}{l}\overline{-} \\
- \\
- \\
- \\
-\end{array}$ \\
\hline Foreign country & $\begin{array}{l}\text { Consumption } \\
\text { Capital Intensity } \\
\text { Net Foreign Assets } \\
\text { Financial Wealth } \\
\text { After-tax Interest Rate }\end{array}$ & $\begin{array}{l}+ \\
+ \\
- \\
0 \\
-\end{array}$ & $\begin{array}{l}{ }^{b} \\
+ \\
- \\
- \\
-\end{array}$ & $\begin{array}{l}-^{c} \\
0 \\
0 \\
0 \\
0\end{array}$ & $\begin{array}{l}+^{b} \\
- \\
+ \\
+ \\
+ \\
+\end{array}$ \\
\hline
\end{tabular}

Notes: $a$ : The impact effects are for the case $\sigma=1$, i.e. logarithmic utility.

$b$ : As long as $\mathrm{z}$ and $\sigma$ are not too large.

$c$ : As long as $z$ is not too large.

Note also that most of the steady state results are based on the premise that $\gamma=c+\beta k(1-\sigma)$ is positive. 
in the international interest rate, consumption increases both at home and abroad in the short run.

It is of interest to briefly compare the effects of a source-based tax to those of a residence-based tax (likewise listed in Table 1$)^{10}$ the overall impression is that the two types of capital taxes have quite different macroeconomic implications, not the least for the foreign country.

The main effect of a rise in the residence-based tax is to depress saving in the home country, as the fall in the net interest rate raises human capital and thereby consumption there 〈see (1) $)$. Thereby world saving falls, and with investment incentives unchanged this leads over time to an increase in the world interest rate $r$. Lower savings domestically reduce financial wealth in the home country, and both components hereof, the capital stock and the stock of foreign assets, will decline. Due to the drop in financial wealth, consumption declines in the long run, too. Finally, the domestic after-tax interest rate $r$ will likewise drop.

The picture is somewhat different in the rest of the world. It is hit mainly by the drop in savings in the home country and the associated increase in the world interest rate. The latter induces higher savings abroad, and since the foreign capital stock declines in the course of time there is an even greater rise in the stock of international assets abroad. The stronger financial asset position in the foreign country will enable steady state consumption to increase.

The short run effects of the residence-based tax are simple. All stocks are unaffected, since the tax is neutral to investment decisions. Apart from the obvious fall in the net interest rate at home, only consumption in the two countries is influenced by the tax change - it will rise in the home country because of the more limited incentive to save, while it will decline abroad in expectation of a rising world interest rate.

The instantaneous improvement in the domestic net external position following the source-based tax corresponds well to the trade balance result in Bovenberg [1989] for his one-good case. He also finds, though, that when

10. The necessary formulas can be found in a technical appendix available upon request. The qualitative results for the residence principle are the same as those in Nielsen [1992]. 
imperfect substitution between domestic and foreign goods is allowed, the trade balance may deteriorate. Likewise, Sibert [1990] finds that her 'investment tax' will lower wages and investment at home, and that the world interest rate will also drop. This accords well with our results.

\section{Intergenerational Welfare Consequences Abroad of a Source-based Tax}

This section briefly considers generational welfare consequences abroad of a change in the home country's source-based capital income tax.

The basis for individual welfare is, of course, (the development in) personal consumption. We have already seen in the previous section that for the source-based tax, consumption abroad will increase in the short run, whereas it will fall in the long run. Does this mean that the tax takes from future generations in the foreign country in order to transfer to present generations there?

Only a stringent welfare investigation will deliver the answer to this and similar questions. We here sketch how to proceed with such an investigation. ${ }^{11}$

To limit the complexity of the study we shall assume current-period utility functions to be logarithmic, i.e. that $\sigma$ is equal to one. ${ }^{12}$ Consider an individual at home born at time $s(s>0$ means a future generation; $s=0$ is taken to mean the average individual alive at time zero, in the sense that his financial wealth equals per capita financial wealth in the economy). His consumption develops over time according to

$$
c(s, t)=c_{s} \exp \left(\int_{s}^{t}(\tilde{r}(v)-\delta) d v\right)
$$

where $c_{s}$ stands for his initial consumption $c(s, s)$ (or, if $s=0$, the average consumption $c(0)$ at time zero).

Furthermore, we note that the initial consumption level $c_{s}$ is given by

11. The welfare analysis below unavoidably suffers form mixing efficiency and intergenerational redistribution. The separation of efficiency and distribution done by Bovenberg (1993) is not applicable in the present context because of the endogeneity of the world interest rate.

12. We believe, however, that the qualitative results below also hold for non-unitary values of $\sigma$, at least as long as the parameter $\gamma$ stays positive. 


$$
c_{s}=(\delta+\lambda)\left(j_{s}+a_{s}\right)
$$

where $j_{s}$ and $a_{s}$ denote initial human wealth and financial wealth, respectively. In case $s$ is greater than zero, $a_{s}$ is of course zero; for s equal to zero, it is positive, as it in fact equals the per capita stock of capital. The percentage change in initial consumption can be written

$$
\hat{c_{s}}=\varepsilon_{s} \hat{j}_{s}+\left(1-\varepsilon_{s}\right) \tilde{a}_{s}
$$

where a "hat" signifies a relative change and $\varepsilon_{s}$ the share of human capital in total wealth ( $\varepsilon_{s}$ is thus equal to one for $s>0$ and less than one, in fact equal to $(\lambda+\mu)^{-1}(\delta+\lambda+\mu-\tilde{r})$, for $\left.s=0\right)$. Notice that $\hat{a}_{s}=0$, since financial wealth is not affected by the tax change on account of the absence of asset revaluation effects in the model. Human capital $j_{s}$ on the part of the individual is

$$
j_{s}=\int_{s}^{\infty} \omega(t) \exp \left(-\int_{s}^{t}(\tilde{r}(v)+\lambda) d v\right) d t
$$

in which $\omega(t)$ denotes the sum of the wage rate and the rate of public transfer at time $t$.

Using the above information we can express the effect of tax changes on individual welfare as

$$
\begin{aligned}
d W_{s}= & \int_{s}^{\infty} e^{-(\delta+\lambda)(t-s)}\left[\int_{s}^{\infty}(\tilde{r}+\lambda) \omega^{-1} \varepsilon_{s} e^{-(\tilde{r}+\lambda)(y-s)} d w(y) d y\right. \\
& \left.-\varepsilon_{s} \int_{s}^{\infty} e^{-(\tilde{r}+\lambda)(v-s)} d \tilde{r}(v) d v+\int_{s}^{t} d \tilde{r}(v) d v\right] d t
\end{aligned}
$$

This formula shows that a resident at home will be affected by the sourcebased tax in three ways: $(i)$ the sum of wage and transfer payments at future dates is altered; (ii) human capital in addition changes because the net interest rate used to discount future wages-cum-transfers changes; and (iii), the slope of the consumption trajectory changes in line with the interest rate.

The change in the sum of wage and transfer payments is (suppressing time arguments)

$$
\begin{aligned}
d \omega= & d k\left[-q^{\prime \prime}(k) k(1-z)(1-u)+R z+r u\right]+r u d f \\
& +R k(1-u) d z+R k(1-z) d u
\end{aligned}
$$

The development in $\tilde{r}, k$ and $f$ over time can now be found with the use of 
solutions for the average and difference economies. Here we simply state the end results for welfare consequences of a domestic source-based tax for the following individuals: $(i)$ foreign residents born in the distant future; and (ii) the average foreign citizen living at the time of the policy change. ${ }^{13}$ The point of departure is, of course, expressions parallel to (22) and (23) for the foreign country.

\section{A. Welfare Impacts Abroad in the Long Run}

We can write the impact on welfare of a foreign resident being born in the distant future as

$$
\begin{aligned}
d W_{\infty}^{*}= & -w^{-1}(\delta+\lambda)^{-2}(\tilde{r}+\lambda)^{-1}(1-u)(1-z) q^{\prime \prime}(k) \cdot[(\tilde{r}+\lambda)(\delta+\lambda) k \\
& -(\tilde{r}-\delta) w] d k_{\infty}^{*}+w^{-1}(\delta+\lambda)^{-1}(R z+r u) d k_{\infty}^{*}-(1 / 2) r u d f_{\infty}^{d}
\end{aligned}
$$

(where the subscript " $\infty$ " again refers to steady state levels). The coefficient of $d k_{\infty}^{*}$ in the first term on the right hand side can be seen to be positive. ${ }^{14}$ Accordingly, for small values of $u$ and $z$ the welfare change is determined by what happens to the foreign capital stock in the long run. We conclude, therefore, that with low values of initial capital income tax rates an increase in the home country source-based tax will benefit foreigners' welfare in the long run. The reason must be that the increase in the foreign capital stock will permit a rise in the wage rate for these individuals.

If, on the contrary, a residence-based capital income tax is raised, this will . cause a fall in the foreign capital stock in the long run and hence be detrimental to welfare of foreigners born in the distant future.

It is intriguing to observe that Sibert [1990] derives that both her "investment tax' and her 'savings tax' will benefit foreigners in the long run. The different conclusion for the residence-based tax is probably best ascribed to the extreme saving and retirement behaviour in the conventional two-period OLG model. Finally, we may note that also Giovannini [1989] and Sørensen

13. Further documentation of our calculations can be found in a technical appendix available upon request.

14. This is so because in the former steady state

$$
[(\tilde{r}+\lambda)(\delta+\lambda) k-(\tilde{r}-\delta) w]=-\Delta_{1}^{-1} w(\tilde{r}-\delta)(\tilde{r}-\mu)(\tilde{r}+\lambda)>0
$$


[1990] observe, within simpler contexts, that as regards foreign long run welfare only the residence-based tax appears to constitute a beggar-thyneighbour policy.

\section{B. Welfare Effects Abroad in the Short Run}

Compared to the previous analysis, the study of the welfare change for the average citizen abroad at time zero is complicated by the fact that the variation over time in wages-cum-transfers and in the net interest rate must be taken into account.

Because of this, the general formula for the impact on welfare on behalf of the average individual abroad at the time of the policy shock is somewhat involved (it is stated in the Appendix). The same factors as in subsection 5.A are relevant here, but in addition the speed of adjustment of the average and difference economies - as given by the eigenvalues $\eta_{a}$ and $\eta_{d}$ - generally enters the formula.

We shall therefore concentrate on the case where all capital tax rates are zero to start with.

This simplifies the formula into

$$
\begin{aligned}
d W_{0}^{*}= & (\delta+\lambda)^{-2}(\tilde{r}+\lambda)^{-1}\left(-q^{\prime \prime}\right)(\tilde{r}-\delta) \\
& \cdot\left[\left(\delta+\lambda-\eta_{a}\right)^{-1}\left(\tilde{r}+\lambda-\eta_{a}\right)^{-1} \eta_{a}\left(\tilde{r}+\delta+2 \lambda-\eta_{a}\right) d k_{\infty}^{a}+d k^{d} / 2\right]
\end{aligned}
$$

The coefficient to $d k_{\infty}^{a}$ is negative, while that of $d k^{d}$ is positive; for the source-based tax, the sign of either capital stock change is, however, negative. Using expressions for these, one finds that the sign of the welfare impact is the same as that of the expression

$$
\kappa=\eta_{a}\left(\tilde{r}+\delta+2 \lambda-\eta_{a}\right) \Delta_{a}^{-1}\left(-q^{\prime \prime}\right) c\left(\delta+\lambda-\eta_{a}\right)^{-1}\left(\tilde{r}+\lambda-\eta_{a}\right)^{-1}-1
$$

Close inspection of the $\kappa$ expression reveals that it is monotonically increasing in $\left(-q^{\prime \prime}\right)$, albeit contained by the interval $(-1,0)$. We therefore conclude that the introduction of a source-based capital income tax in the home country will on impact cause a deterioration of welfare on the part of the average foreigner - and apparently the more so, the closer is $q^{\prime \prime}$ to zero, and hence the better are possibilities for capital-labour substitution in pro- 
duction. The reason for the welfare deterioration is that the return to the stock of financial assets accumulated by the average foreigner falls (and that this dominates the wage increase which he experiences).

Once again, we may compare with a residence-based tax. Since this will over time cause a decline in the average capital stock in the world economy while leaving the difference between national capital stocks unchanged, it is clear from (25) that the residence-based tax will benefit the average foreign citizen on impact.

The welfare evaluation for situations in which a non-negligible existing source-based tax is increased even further will incorporate terms representing how existing distortions in the foreign country will be affected. We shall leave this investigation (in which formula (A.10) in the appendix may be helpful) to the interested reader.

\section{Conclusion}

This paper has dealt with the international spill-overs of capital income taxation in interdependent economies. We have focused primarily on the socalled source principle and have emphasized the implications of a sourcebased capital tax for the development over time in the world interest rate and in investment, consumption, saving and international indebtedness at home and abroad. We also examined some intergenerational welfare consequences of domestic capital income taxation for foreign residents. Finally, we have at various stages compared source-based taxation with taxation according to the residence principle.

The method of analysis consisted in adapting a continuous-time overlapping generations model, developed along the lines suggested by Blanchard [1985] and Buiter [1988], to a two-country setting with capital accumulation and taxes on capital income. This framework permits a non-trivial macroeconomic analysis of the interrelationship between large interdependent countries. In addition, it provides a tool for the analysis of the welfare impacts of taxation on different generations abroad.

We shall not reiterate here the qualitative impact and steady state effects of taxation on macroeconomic key variables at home and abroad; instead we just refer to Table 1 above. Nor shall we go into detail with our results on 
generational welfare impacts. But we do want to draw attention to striking contrasts between overall macroeconomic and individual welfare effects of capital income taxes:

For instance, an increase in the domestic source-based capital income tax will lower consumption per capita abroad in the long run, whereas individual welfare on the part of foreign citizens born in the distant future will actually improve. Similarly, the increase in the source-based tax will cause an increase in foreign consumption in the short run, but welfare on the part of the average foreign citizen alive at the time of the policy shock will likely deteriorate. So the welfare effects abroad of domestic capital income taxation cannot at all be gauged by looking at macroeconomic variables!

One reason for this paradox is that while all foreign individuals at a given time are affected to the same degree, when it comes to their wage income, the older ones with the larger financial wealth are more sensitive to variations in the rate of return on their assets. Moreover, when tax rates abroad are positive initially, such taxation is "intergenerationally non-neutral" in the words of Keuschnigg [1994], as wealth varies across generations, while the revenue from taxation is distributed in the form of equal lump-sum transfers to everyone.

A further remark on capital stock adjustment is in order. To be able to study tax policy in large countries with generational overlap we abstained from modeling sluggish adjustment of physical capital stocks. Instead we incorporated instantaneous reshuffling of capital across countries, whereby capital stocks in the two countries could respond immediately to a change in source-based taxes. Nielsen \& Sørensen [1991] and Bovenberg [1993, 1994] carry out studies of capital income taxation with adjustment costs in investment in models otherwise akin to the one in this paper, but for a small open economy only. Interesting asset (capital stock) revaluation effects then enter the analysis. Perhaps future work will find a way to integrate the respective approaches.

Another direction for future research, well worth consideration, is endogenizing labour supply by including disutility of work in the utility function. 


\section{Appendix}

We first show that, as claimed in footnotes 4 and 7 in the text, the average and difference economy systems are saddle-point stable with logarithmic utility, Cobb-Douglas production structure, no depreciation and no initial taxes.

In this special case, both systems degenerate to two-equation systems only. It therefore suffices to show that the determinants $\Delta_{a}$ and $\Delta_{d}$ are negative. With the current assumptions,

$$
\Delta_{a}=(r-\delta)(r-\mu)-\beta(\delta+\lambda)+c q^{\prime \prime}
$$

while $\Delta_{d}$ is the same, except for the absence of the third term. Since concavity implies $q^{\prime \prime}<0$, it is enough to show that with the level of the international interest rate prevailing in steady state, $\Delta_{d}$ is negative. The positive interest rate, at which $\Delta_{d}$ is equal to zero, is

$$
r_{0}=\frac{\delta+\mu}{2}+\sqrt{\left(\frac{\delta+\mu}{2}\right)^{2}+\lambda(\delta+\beta)}
$$

All we have to do, then, is demonstrate that the steady state interest rate is less than $r_{0}$.

The equations for the dynamic evolution of average consumption and capital stock are, in the special case,

$$
\begin{aligned}
& \dot{c}^{a}=(r-\delta) c^{a}-\beta(\delta+\lambda) k^{a} \\
& \dot{k}^{a}=q\left(k^{a}\right)-\mu k^{a}-c^{a}
\end{aligned}
$$

Introducing a Cobb-Douglas function with factor share of capital denoted by $\alpha$, it must hold in steady state that

$$
(r / \alpha-\mu)(r-\delta)-\lambda(\delta+\beta)=0
$$

The positive solution to this equation yields the steady state interest rate

$$
r_{\infty}=\frac{\delta+\mu \alpha}{2}+\sqrt{\left(\frac{\delta+\mu \alpha}{2}\right)^{2}+\alpha \lambda(\delta+\beta)}
$$


It is clear by comparison with expression (A.1) that the steady state interest rate is smaller than $r_{0}$, indicating that the steady state will be saddle-path stable for both the average and the difference economies.

Next, we substantiate some of the impact and steady state effects for the source-based tax presented in Table 1 . In the table the impact effects are for the logarithmic current-period utility case, i.e. for the case where $\sigma=1$ and $\theta^{-1}=(\delta+\lambda)$.

For the difference system we can report the following impact effects:

$$
\begin{aligned}
& \frac{d k^{d}}{d z^{d}}=\frac{R}{(1-z) q^{\prime \prime}(k)}<0 \\
& \frac{d f^{d}}{d z^{d}}=-\frac{d k^{d}}{d z^{d}}>0 \\
& \frac{d c^{d}}{d z^{d}}=\frac{z \beta R^{2} \eta_{d}}{\Delta_{d}(1-z) q^{\prime \prime}(k) \theta\left(\tilde{r}-\delta-\eta_{d}\right)} \leq 0
\end{aligned}
$$

$\eta_{d}$ being the negative eigenvalue of the Jacobian of the difference system's state-space form. Notice that the difference between capital stocks in the two countries is constant during the entire dynamic adjustment process, whereas the differences in consumption and in the net foreign asset position in the two countries move in the course of time.

The impact effects for the average economy read:

$$
\begin{aligned}
& \frac{d k^{a}}{d z^{a}}=0 \\
& \frac{d c^{a}}{d z^{a}}=\frac{c R \eta_{a}(1-u)}{\Delta_{a}}>0
\end{aligned}
$$

$\eta_{a}$ is the negative eigenvalue of the Jacobian of the average economy equation system.

From equation (12) in the text it is then trivial to derive the impact and steady state effects of a change in the source-based tax on the global interest rate. The former is

$$
\frac{d r}{d z}=-\frac{R}{2}<0
$$


The steady state effect is given by:

$$
\frac{d r}{d z}=\frac{-R \Delta_{1}}{2 \Delta_{a}}<0
$$

Finally, using the method sketched in Section 6 in the text, it is possible to derive an expression, in terms of steady state average and difference variables, of the welfare change of the average foreign individual at the time of the policy change:

$$
\begin{aligned}
d W_{0}^{*}= & \frac{1}{2} \varepsilon_{0} r u \eta_{d}(\delta+\lambda)^{-1}\left(\tilde{r}+\lambda-\eta_{d}\right)^{-1}-\omega^{-1} d f_{\infty}^{d} \\
& -\frac{1}{2}(\delta+\lambda)^{-1} \cdot\left\{(1-z)(1-u)(\tilde{r}+\lambda)^{-1} q^{\prime \prime}(k)(\tilde{r}-\delta)(\delta+\lambda\right. \\
& \left.+\varepsilon_{0} \omega^{-1}\left[\eta_{d}\left(\eta_{d}-\tilde{r}-\lambda\right)^{-1} r u+R z\right]\right\} d k^{d} \\
& -\eta_{a}(\delta+\lambda)^{-1}\left(\tilde{r}+\lambda-\eta_{a}\right)^{-1}\left[\varepsilon_{0} \omega^{-1}(R z+r u)\right. \\
& +(1-z)(1-u)(\tilde{r}+\lambda)^{-1}(\delta+\lambda)^{-1}\left(\eta_{a}-\delta-\lambda\right)^{-1} . \\
& \left.q^{\prime \prime}(k)\left(\eta_{a}-\tilde{r}-2 \lambda-\delta\right)(\tilde{r}-\delta)\right] d k_{\infty}^{a}
\end{aligned}
$$

In deriving (A.10) we have used that, surprisingly, $\varepsilon_{0} \omega^{-1}[\omega+(\tilde{r}+\lambda) k]=1$.

\section{References}

Aoki, Masanao [1981], Dynamic Analysis of Open Economics, Academic Press, New York.

Blanchard, Olivier J. [1985], "Debt, Deficits and Finite Horizons," Journal of Political Economy 93; pp. 223-47.

Bovenberg, A. Lans [1989], "The Effects of Capital Income Taxation on International Competitiveness and Trade Flows," American Economic Review, 79; pp. 1045-64

Bovenberg, A. Lans [1994], "Capital Taxation in the World Economy,” In van der Ploeg, Frederick (Ed.), Handbook of International Macroeconomics, Oxford. 
Bovenberg A. Lans [1993], "Investment-Promoting Policies in Open Economies: The Importance of Intergenerational and International Distributional Effects," Journal of Public Economics, 51; pp. 3-54.

Buiter, Willem H. [1988], "Death, Birth, Productivity Growth and Debt Neutrality," Economic Journal, 98; pp. 279-93.

Frenkel, Jacob H., Razin, Assaf and Efraim Sadka [1991], International Taxation in an Integrated World, MIT Press, Cambridge.

Giovannini, Alberto [1989], "National Tax Systems versus the European Capital Market," Economic Policy, October; pp. 346-86.

Ihori, Toshihiro [1991], "Capital Income Taxation in a World Economy: A Territorial System versus a Residence System," Economic Journal 101; pp. 958-965.

Keuschnigg, Christian [1994], "Dynamic Tax Incidence and Intergenerationally Neutral Reform," European Economic Review, 38; pp. 343-66.

Nielsen, Søren Bo [1992], "Capital Income Taxation in a Growing World Economy," Journal of Economics, 55; pp. 77-99

Nielsen, Søren Bo and Peter Birch Sørensen [1991], "Capital Income Taxation in a Growing Open Economy," European Economic Review, 34; pp. 179-97.

Sibert, Anne C. [1990], "Taxing Capital in a Large, Open Economy," Journal of Public Economics, 41; pp. 297-317.

Sinn, Hans-Werner [1987], Capital Income Taxation and Resource Allocation, North-Holland, Amsterdam.

Sinn, Hans-Werner [1987], "Why Taxes Matter: Reagan's Accelerated Cost Recovery System and the US Trade Deficit," Economic Policy, 1; pp. 240-50.

Sørensen, Peter Birch [1991], "On the Welfare Gains from International Fiscal Coordination," Discussion Paper 90-04, Institute of Economics, University of Copenhagen [1990], An abbreviated version appears in R. Prud'homme (Ed.), Public Finance with Several Levels of Government, Brussels. 